\title{
Wood Carbon Based Single-Atom Catalyst for Rechargeable Zn-Air Batteries
}

Linxin Zhong ${ }^{\text {a }}$, Chengyu Jiang ${ }^{\text {a }}$, Mengting Zheng ${ }^{\text {b }}$, Xinwen Peng ${ }^{\text {a }}$, Tongchao Liu $^{\mathrm{c}}$, Shibo Xi ${ }^{\mathrm{d}}$, Xiao Chi ${ }^{\mathrm{e}}$, Qinghua Zhang ${ }^{\mathrm{f}}$, Lin $\mathrm{Gu}^{\mathrm{f}}$, Shanqing Zhang ${ }^{\mathrm{b}}$, Ge Shi ${ }^{\mathrm{a}}$, Lei Zhang ${ }^{\text {a }}$, Kunze $\mathrm{Wu}^{\text {a }}$, Zehong Chen ${ }^{\text {a }}$, Tingzhen Li ${ }^{\text {a, }}$, Mouad Dahbi ${ }^{\mathrm{g}}$, Jones Alami g, Khalil Amine ${ }^{\mathrm{c} *}$ and Jun $\mathrm{Lu}^{\mathrm{c} *}$

${ }^{\text {a }}$ State Key Laboratory of Pulp and Paper Engineering, South China University of Technology, 381 Wushan Road, Tianhe District, Guangzhou, 510641, P. R. China

${ }^{\mathrm{b}}$ Centre for Clean Environment and Energy and Griffith School of Environment, Griffith University, Gold Coast, QLD 4222, Australia

c Chemical Sciences and Engineering Division, Argonne National Laboratory, Lemont, IL, 60439 USA

${ }^{d}$ Institute of Chemical and Engineering Sciences, A*STAR, Fusionopolis Way, \#20-10, Connexis North Tower,138632, Singapore

e Department of Chemistry and Centre for Advanced 2D Materials (CA2DM), National University of Singapore, 3 Science Drive 3, Singapore, 117543, Singapore

${ }^{\mathrm{f}}$ Songshan Lake Materials Laboratory, Dongguan, Guandong, 523808, China

g Materials Science and Nano-Engineering Department, Mohammed VI Polytechnic University, Ben Guerir, Morocco

${ }^{\#}$ L. Z., C. J., and M. Z. contributed equally to this work.

*Corresponding Authors. E-mail: fexwpeng@scut.edu.cn (X. Peng), junlu@anl.gov (J. Lu), and amine@anl.gov (K. Amine). 


\section{Reagents and materials}

$\mathrm{FeCl}_{3} \cdot 6 \mathrm{H}_{2} \mathrm{O}(98 \%), \mathrm{AlCl}_{3} \cdot 6 \mathrm{H}_{2} \mathrm{O}(99 \%)$, and $\mathrm{ZnCl}_{2}$ (99\%) were purchased from Energy Chemicals (Shanghai, China), Commercial Pt/C (20 wt \%) was acquired from Alfa Aesar (Shanghai, China), and ruthenium dioxide $\left(\mathrm{RuO}_{2}, 99.9 \%\right)$ for electrochemical measurements was purchased from Aladdin (Shanghai, China). All chemicals were received from commercial sources and used without further purification. Deionized water with a resistivity of $18.3 \mathrm{M} \Omega \mathrm{cm}^{-1}$ was used in this work. The wood used in this work is three-year-old eucalyptus (wood logs are naturally dried for 6 months), and acquired from Nanning, Guangxi Province, China. After peeling, the eucalyptus was cut into the required size $(2 \times 2 \times 0.5 \mathrm{~cm})$ and dried in a blast drying oven at $80{ }^{\circ} \mathrm{C}$ for $24 \mathrm{~h}$ before use.

\section{Experimental details}

\section{Preparation of wood treated by $\mathrm{FeCl}_{3}\left(\mathrm{FeCl}_{3}\right.$-wood $)$}

The dried wood was impregnated in an aqueous solution containing $\mathrm{FeCl}_{3}$ with different mass ratios and kept at $80{ }^{\circ} \mathrm{C}$ for $24 \mathrm{~h}$. After drying overnight in an oven at $80{ }^{\circ} \mathrm{C}$, the resulting products are donated in the form of $\mathrm{FeCl}_{3}$-wood. For comparison, wood was treated with $\mathrm{AlCl}_{3}$ and $\mathrm{ZnCl}_{2}$ by the same procedure named $\mathrm{AlCl}_{3}$-wood and $\mathrm{ZnCl}_{2}$-wood.

Preparation of N-doped Single Fe Atoms on Wood-based Porous Carbon (SAC-FeN-WPC)

To synthesize SAC-FeN-WPC-T ( $\mathrm{T}$ stands for carbonization temperature), $\mathrm{FeCl}_{3}$-wood was directly heated to the target temperature $\left(800{ }^{\circ} \mathrm{C}, 900{ }^{\circ} \mathrm{C}\right.$, and $1000{ }^{\circ} \mathrm{C}$ ) at a heating rate of $5{ }^{\circ} \mathrm{C} \mathrm{min}^{-1}$, and the target temperature was kept in 
Ar- $\mathrm{NH}_{3}\left(10 \% \mathrm{NH}_{3}\right)$ flowing in a tube furnace for 2 hours. Finally, the pyrolyzed product was etched in $1 \mathrm{M} \mathrm{HCl}$ solution at $80{ }^{\circ} \mathrm{C}$ for $6 \mathrm{~h}$ to remove inactive $\mathrm{Fe}$ species. The Fe loading on carbonized wood ( $0.8 \mathrm{wt} \%)$ was determined by ICP-OES. $\mathrm{AlCl}_{3}$-wood and $\mathrm{ZnCl}_{2}$-wood were treated in the same way and named $\mathrm{AlCl}_{3}-\mathrm{N}-\mathrm{WPC}$ and $\mathrm{ZnCl}_{2}-\mathrm{N}-\mathrm{WPC}$. N-WPC was prepared by the same heating process but wood without any pretreatment. WPC was prepared by the same heating process in the Ar atmosphere.

\section{Characterizations}

Scanning electron microscope (FE-SEM Merlin, Zeiss) scans under the accelerated voltage of $5 \mathrm{kV}$. The dimension and internal structure of the samples were characterized by a transmission electron microscope combined with a high-resolution imaging feature (TEM, JEM-2100F) operating at $200 \mathrm{kV}$. The chemical composition of the sample was determined by X-ray photoelectron spectroscopy (Thermo Science ESCALAB 250Xi) with an exciting source of $\mathrm{Al} \mathrm{K \alpha}(1286.6 \mathrm{eV})$. The element analysis of iron in solid samples was carried out by Optima 8300 (PerkinElmer) inductively coupled plasma atomic emission spectrometer (ICP-OES). The X-ray diffraction spectra of $\mathrm{Cu}-\mathrm{K}$ radiation $(40 \mathrm{kV}$ and $40 \mathrm{~mA}, \mathrm{X}=0.15418 \mathrm{~nm})$ were recorded by Brook D8 diffractometer. The Raman spectrum was carried out by a Raman spectrometer (Labram Aramis-Horiba Jobin Yvon) with an excitation wavelength of $532 \mathrm{~nm}$. The $\mathrm{N}_{2}$ adsorption-desorption isotherm (Micromeritics, ASAP 2460) was measured at $-196{ }^{\circ} \mathrm{C}$ to analyze the Brunauer-Emmett-Teller (BET) specific surface area (SSA) and pore structure. Before analysis, the sample was degassed in a vacuum of $180{ }^{\circ} \mathrm{C}$ for at least 12 hours.

Room-temperature ${ }^{57} \mathrm{Fe}$ Mössbauer spectroscopy. ${ }^{57} \mathrm{Fe}$-enriched samples were prepared by dissolving $30 \mathrm{mg}$ of ${ }^{57} \mathrm{Fe}$ foil (Isoflex) in $5 \mathrm{~mL}$ of concentrated $\mathrm{HCl}$ with 
stirring at $80{ }^{\circ} \mathrm{C}$ until complete dissolution. Add $5 \mathrm{~mL}$ of the above ${ }^{57} \mathrm{FeCl}_{3}$ clear solution to $5 \mathrm{~mL}$ of ethanol and $10 \mathrm{~mL}$ of the mixed solution then drying at $80{ }^{\circ} \mathrm{C}$ to obtain the SAC precursor. Carbonize the precursor at $900{ }^{\circ} \mathrm{C}$ for $2 \mathrm{~h}$ in $10 \% \mathrm{NH}_{3}$ atmosphere. Finally, the pyrolyzed product was etched in $1 \mathrm{M} \mathrm{HCl}$ solution at $80{ }^{\circ} \mathrm{C}$ for $6 \mathrm{~h}$ to remove inactive ${ }^{57} \mathrm{Fe}$ species. The ${ }^{57} \mathrm{Fe}$ Mössbauer measurements were performed with a proportional counter and a Topologic 500A spectrometer with ${ }^{57} \mathrm{Co}$ (Rh) as a $\gamma$-ray radioactive source. A Fe foil was used to calibrate the velocity.

ORR measurements. Electrochemical experiments including cyclic voltammetry (CV), linear sweep voltammetry (LSV), and cycling ability were carried out on a CHI760E electrochemical workstation (Shanghai Chenhua, China) in a three-electrode system. Glass carbon $\left(\mathrm{GC}, \mathrm{S}=0.196 \mathrm{~cm}^{2}\right.$ ) rotating disk, Pt wire and $\mathrm{Ag} / \mathrm{AgCl}$ were used as working electrode, the counter electrode, and reference electrode, respectively. Before use, the GC electrode was polished using an aqueous alumina power on a polishing pad to remove impurity adsorbed on the surface. The working electrode was prepared as follows: $5 \mathrm{mg}$ carbon sample (or commercial Pt/C, $20 \mathrm{wt} \%$ ) was dispersed in $1 \mathrm{~mL}$ ethanol solution (containing $10 \mu \mathrm{L} 5 \mathrm{wt} \%$ Nafion). The suspension was sonicated to form a homogeneous suspension and $10 \mu \mathrm{L}$ suspension was dropped onto the surface of the pre-polished GC electrode. The testing GC electrode was obtained after drying at room temperature. The electrolyte $(0.1 \mathrm{M} \mathrm{KOH})$ was saturated with $\mathrm{N}_{2}$ or $\mathrm{O}_{2}$ before the test. The $\mathrm{CV}$ curves were recorded in $\mathrm{O}_{2}$ and $\mathrm{N}_{2}$ saturated environment at a scan rate of $50 \mathrm{mV} \mathrm{s}^{-1}$, while the LSV curves were conducted using a rotating disk electrode (RDE) in an $\mathrm{O}_{2}$ saturated environment at different rotating rates from 400 to $2025 \mathrm{rpm}$ at a scan rate of $10 \mathrm{mV} \mathrm{s}^{-1}$. For the methanol durability test, $3 \mathrm{M}$ methanol was added to the $\mathrm{O}_{2}$ saturated electrolyte around $1000 \mathrm{~s}$, and the current was recorded 
at $-0.4 \mathrm{~V}$. The stabilities of carbon samples and $\mathrm{Pt} / \mathrm{C}$ were evaluated in $\mathrm{O}_{2}$ saturated electrolyte by chronoamperometry tests $(-0.4 \mathrm{~V}, 10 \mathrm{~h})$.

The kinetic current density $\left(J_{k}\right)$ and electron transferred number (n) during ORR were calculated at different potentials, according to the Koutecky-Levich (K-L) equations:

$\frac{1}{J}=\frac{1}{J_{L}}+\frac{1}{J_{K}}=\frac{1}{B \omega^{\frac{1}{2}}}+\frac{1}{J_{K}}$

$B=0.62 \mathrm{nF} C_{0} D_{0}^{\frac{2}{3}} \vartheta^{-\frac{1}{6}}$

where, $J, J_{L}$ and $J_{K}$ are the current density, diffusion-limiting and kinetic current densities, respectively, $B$ can be determined from the slopes of K-L plot, $\omega$ represents the rotating rate speed in rpm, $F$ is the Faraday constant $\left(96485 \mathrm{C} \mathrm{mol}^{-1}\right)$, Co is the bulk concentration of $\mathrm{O}_{2}\left(1.2 \times 10^{-3} \mathrm{~mol} \mathrm{~L}^{-1}\right.$ in $\left.0.1 \mathrm{M} \mathrm{KOH}\right)$, Do is the diffusion coefficient of $\mathrm{O}_{2}\left(1.9 \times 10^{-5} \mathrm{~cm}^{2} \mathrm{~s}^{-1}\right)$, and $\vartheta$ is the kinetic viscosity of the electrolyte $\left(1.0 \times 10^{-2} \mathrm{~cm}^{2} \mathrm{~s}^{-1}\right)$

Rotating ring-disk electrode (RRDE) measurements were recorded to determine the selectivity of the four-electrode reactions. The hydrogen peroxide yield $\left(\mathrm{H}_{2} \mathrm{O}_{2} \%\right)$ and the electron transfer number (n) were calculated according to the following equations:

$$
\begin{gathered}
H_{2} O_{2}(\%)=200 \times \frac{\frac{I_{R}}{N}}{I_{D}+\frac{I_{R}}{N}} \\
\mathrm{n}=4 \times \frac{I_{D}}{\frac{I_{R}}{N}+I_{D}}
\end{gathered}
$$

where $I_{D}$ is the disk current, $I_{R}$ is the ring current, and $N$ is the ring collection efficiency and is determined to be 0.37 .

\section{Zn-air battery measurements}


The measurements of $\mathrm{Zn}$-air batteries were tested in homemade electrochemical cells under ambient conditions. The air cathode is prepared by dispersing the catalyst ink on the carbon cloth by gas diffusion (catalyst loading is $1 \mathrm{mg} \mathrm{cm}^{-2}$ ). The anode and electrolyte are polished zinc foil and 6.0 M KOH solution containing $0.2 \mathrm{M}$ zinc acetate respectively. The measurement was carried out on the CHI760E electrochemical workstation. According to the results of galvanostatic discharge results, the specific capacity and energy density are calculated and normalized to the mass of consuming $\mathrm{Zn}$. 
(a)

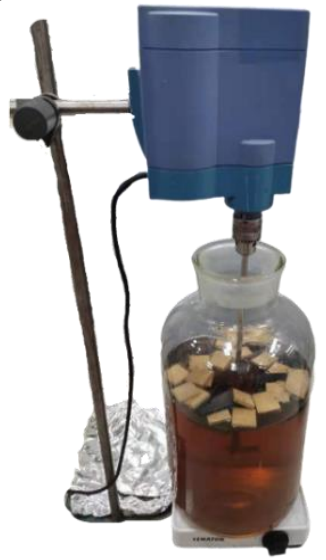

(b)

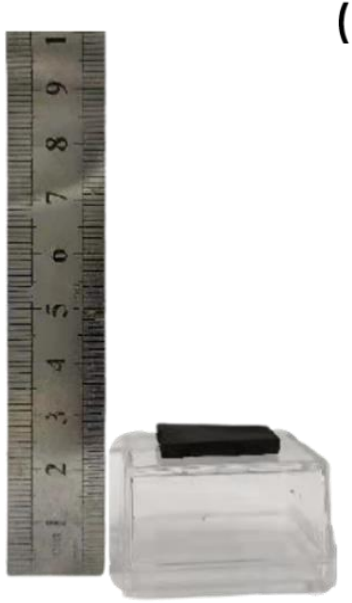

(c)

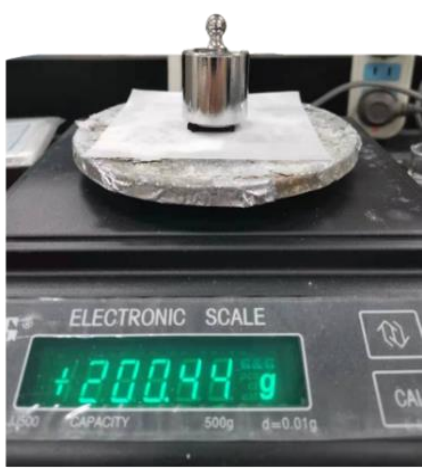

Figure S1. Photos of (a) batch processing of wood with $\mathrm{FeCl}_{3}$, (b) SAC-FeN-WPC Plate and (c) SAC-FeN-WPC Plate ( 0.5 g) supporting > 400 times of its weight (200 g). 

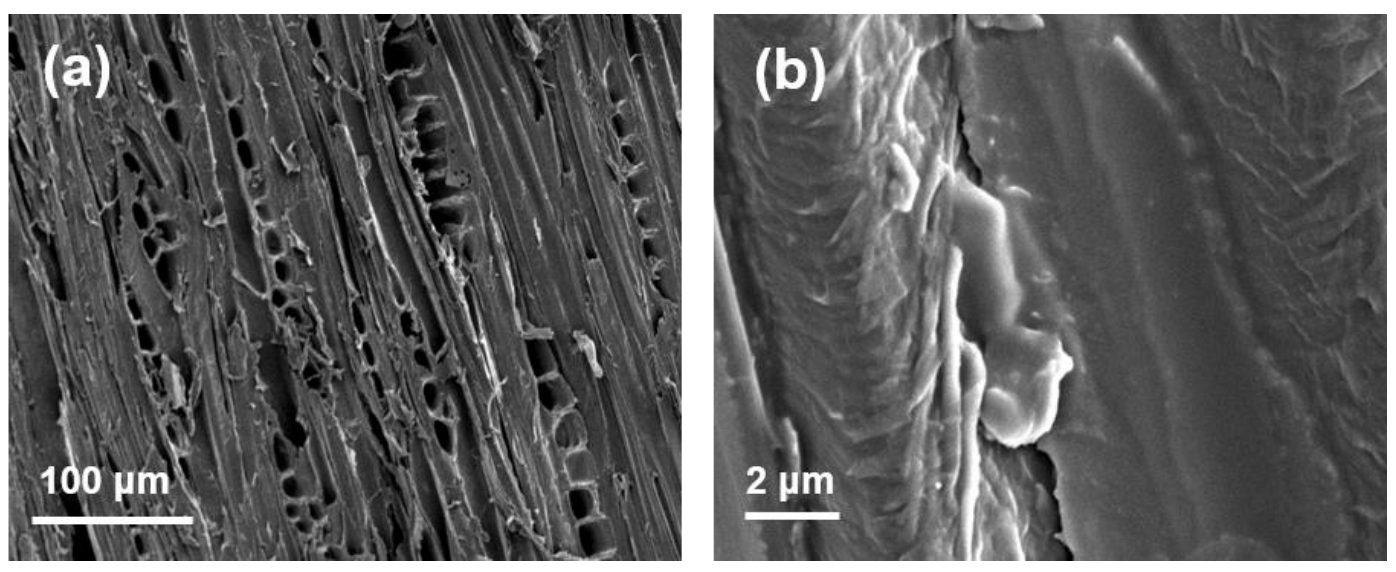

Figure S2. SEM images of natural wood in the vertical direction. 

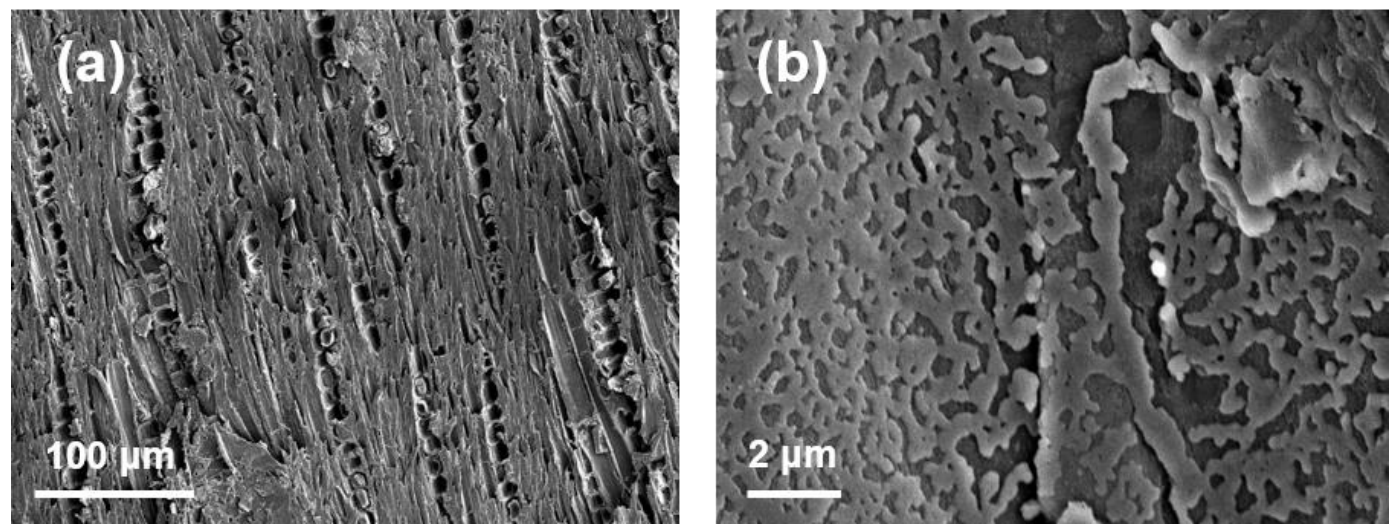

Figure S3. SEM images of $\mathrm{FeCl}_{3}$-wood in the vertical direction. 

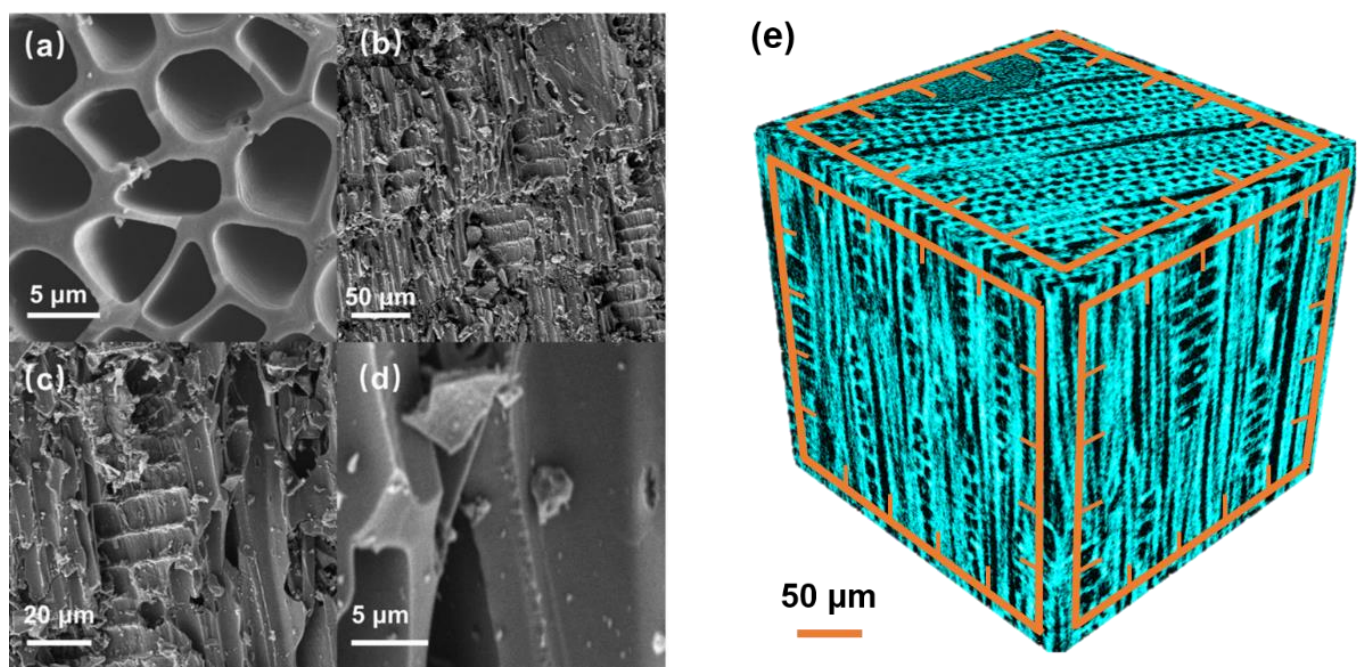

Figure S4. SEM images of N-WPC at various magnifications through (a) parallel and (b-d) vertical directions, and the (e) Microscopic 3D structure of N-WPC. 


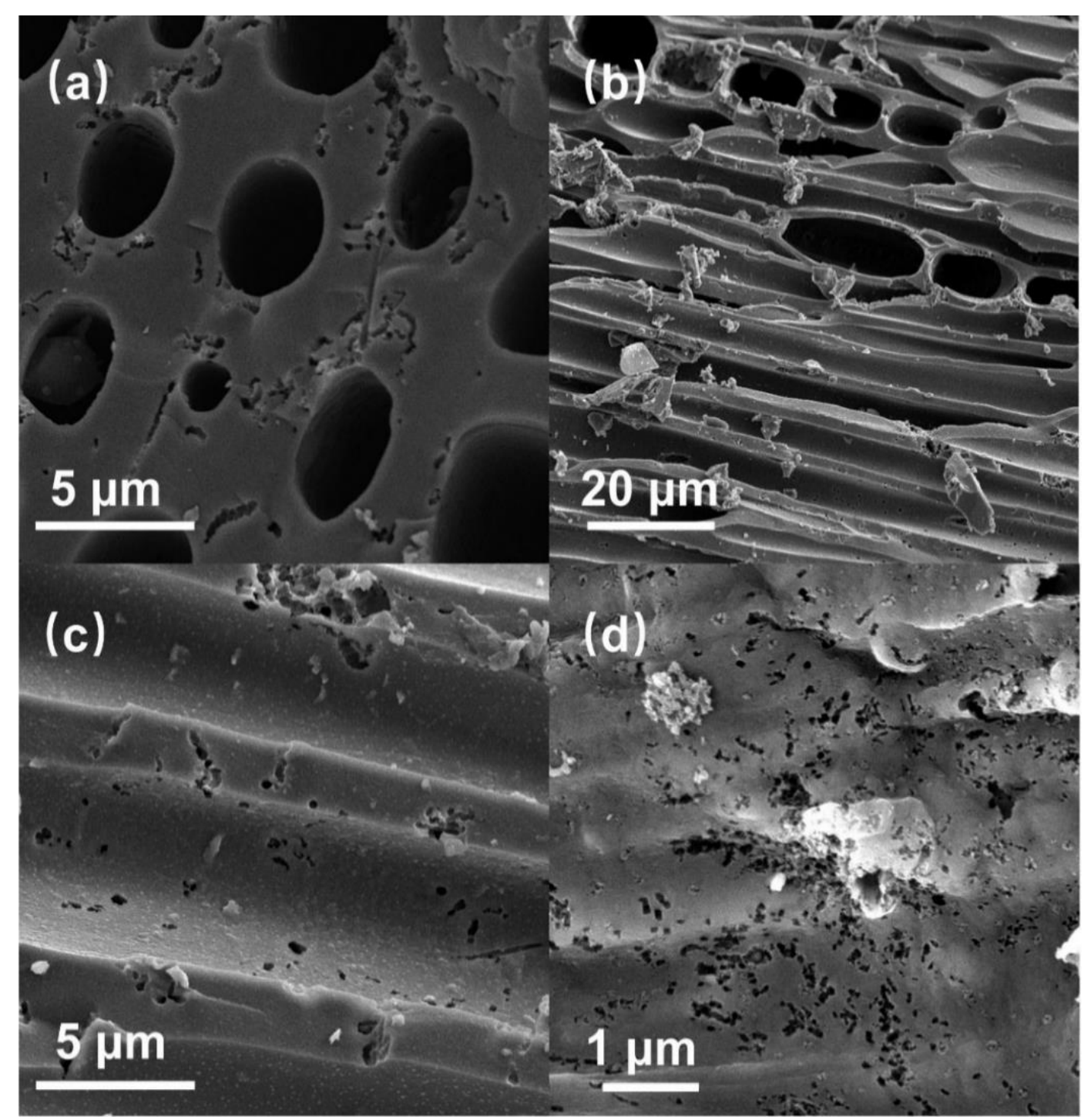

Figure S5. SEM images of SAC-FeN-WPC at various magnifications through (a) parallel and (b-d) vertical directions. 

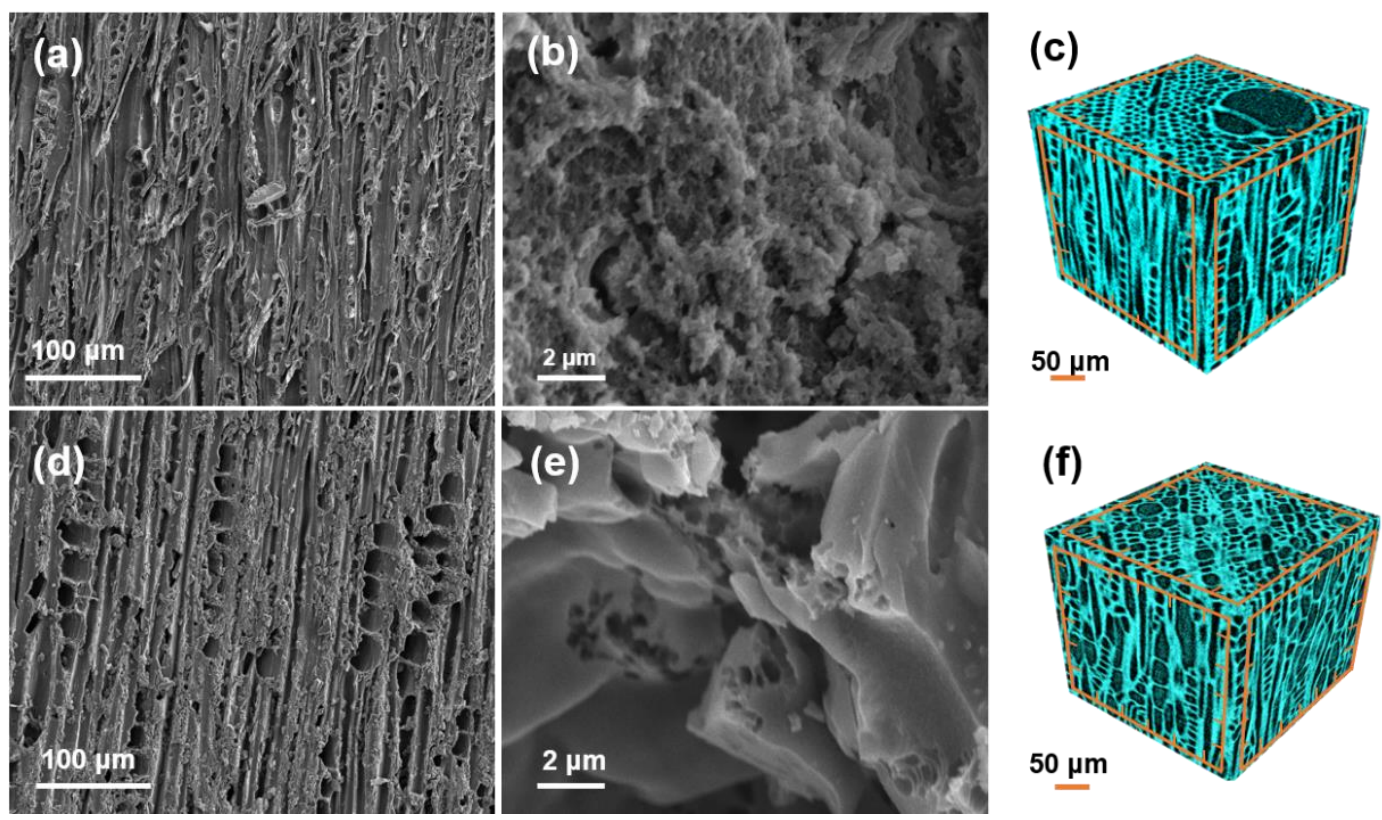

Figure S6. SEM images of (a-c) $\mathrm{ZnCl}_{2}$-wood in the vertical direction and their corresponding Microscopic 3D structure. (d-f) $\mathrm{AlCl}_{3}$-wood in the vertical direction and their corresponding Microscopic 3D structure. 
(a)

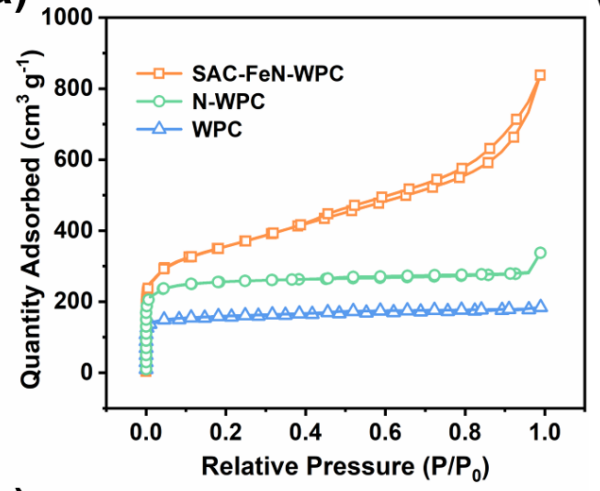

(c)

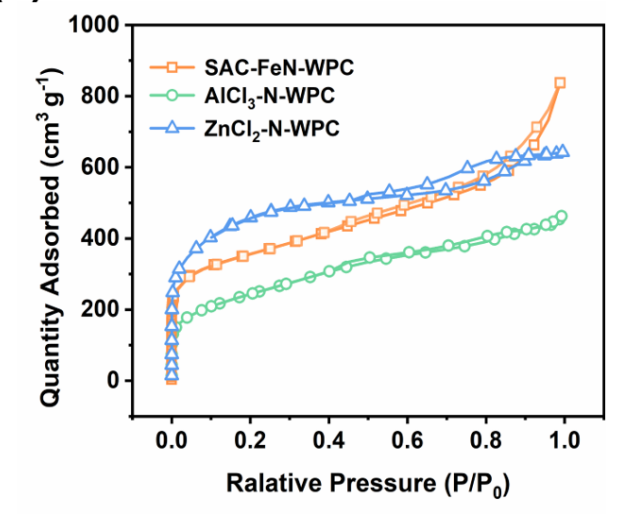

(b)

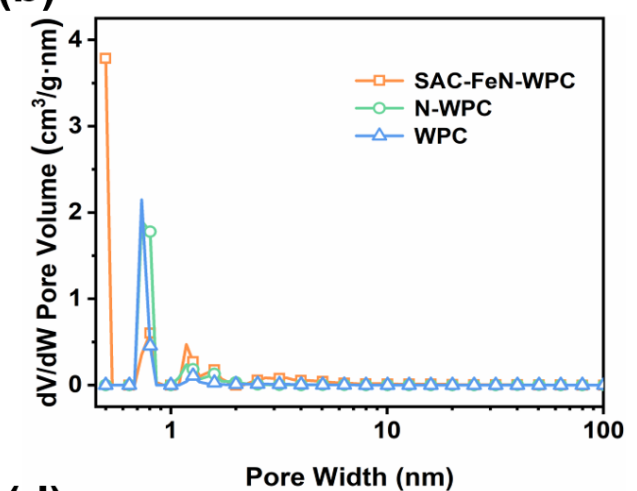

(d)

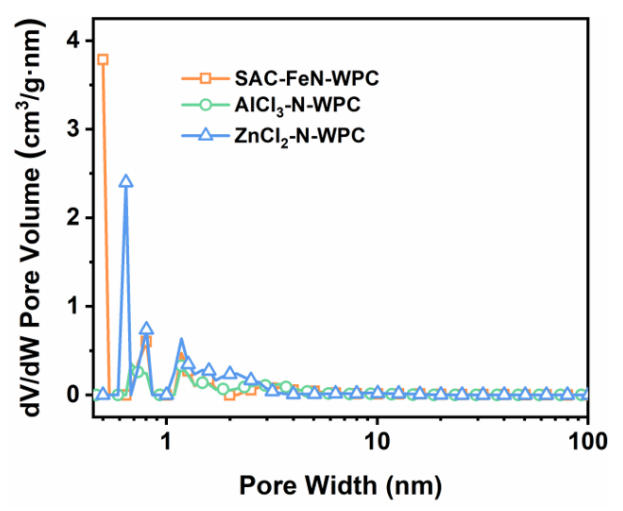

Figure S7. (a) $\mathrm{N}_{2}$ adsorption-desorption isotherms and (b) corresponding pore size distributions of SAC-FeN-WPC, N-WPC, and WPC. (c) $\mathrm{N}_{2}$ adsorption-desorption isotherms and (d) corresponding pore size distributions of SAC-FeN-WPC, $\mathrm{AlCl}_{3}-\mathrm{N}-\mathrm{WPC}$, and $\mathrm{ZnCl}_{2}-\mathrm{N}-\mathrm{WPC}$. 


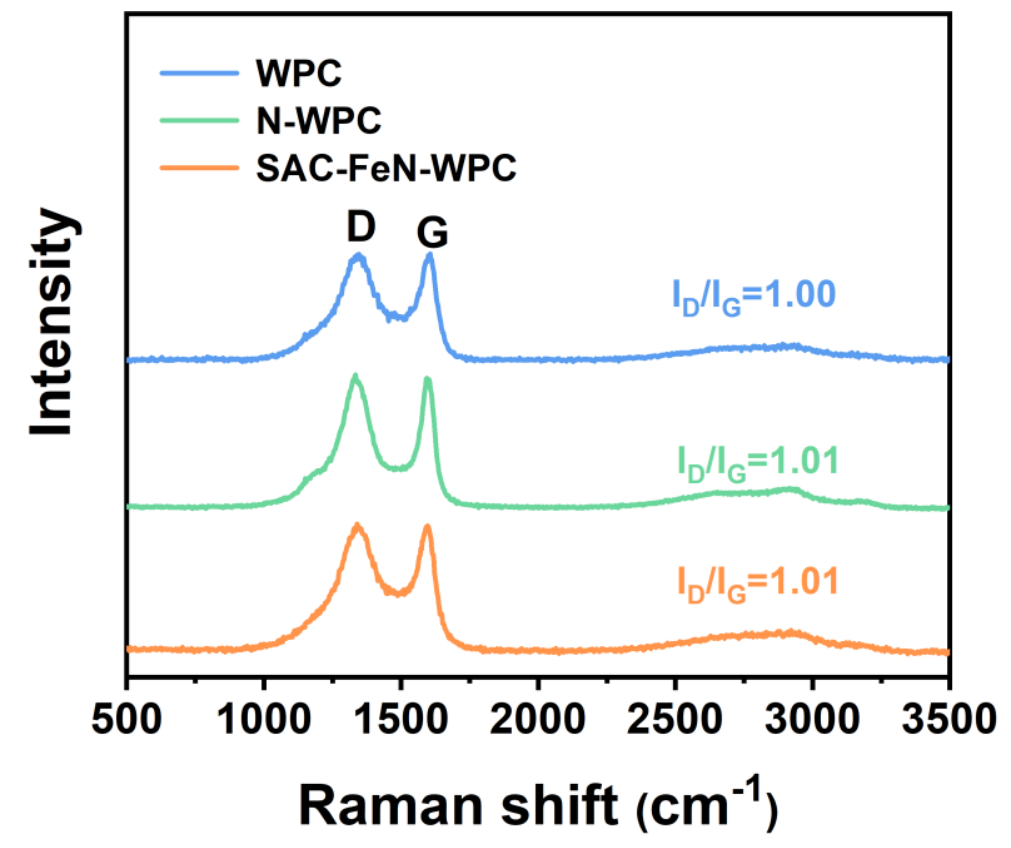

Figure S8. Raman spectra for WPC, N-WPC and SAC-FeN-WPC. 
(a)

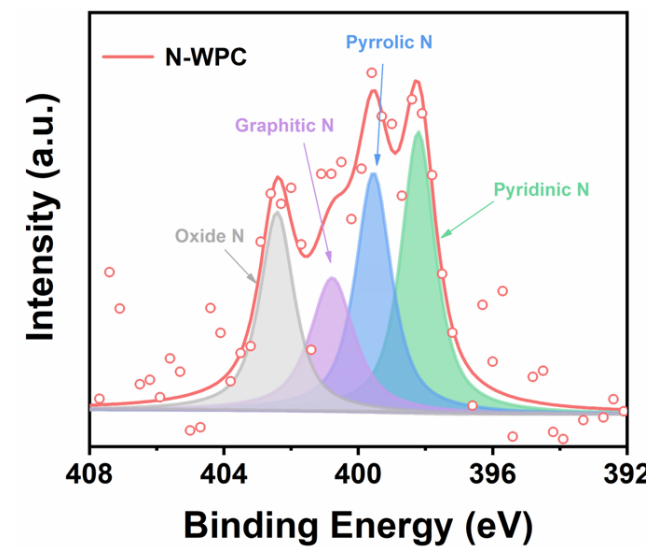

(b)

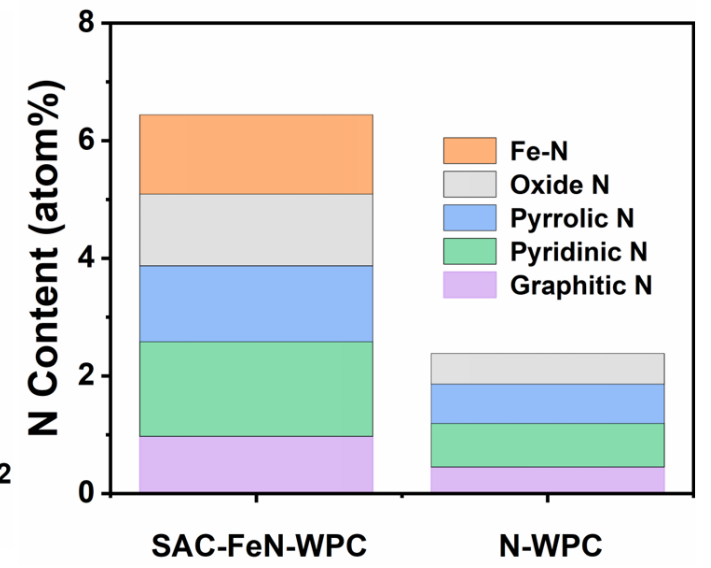

Figure S9. (a) $\mathrm{N}$ 1s high-resolution XPS spectrum of N-WPC. (b) Contents of different N species of SAC-FeN-WPC and N-WPC. 


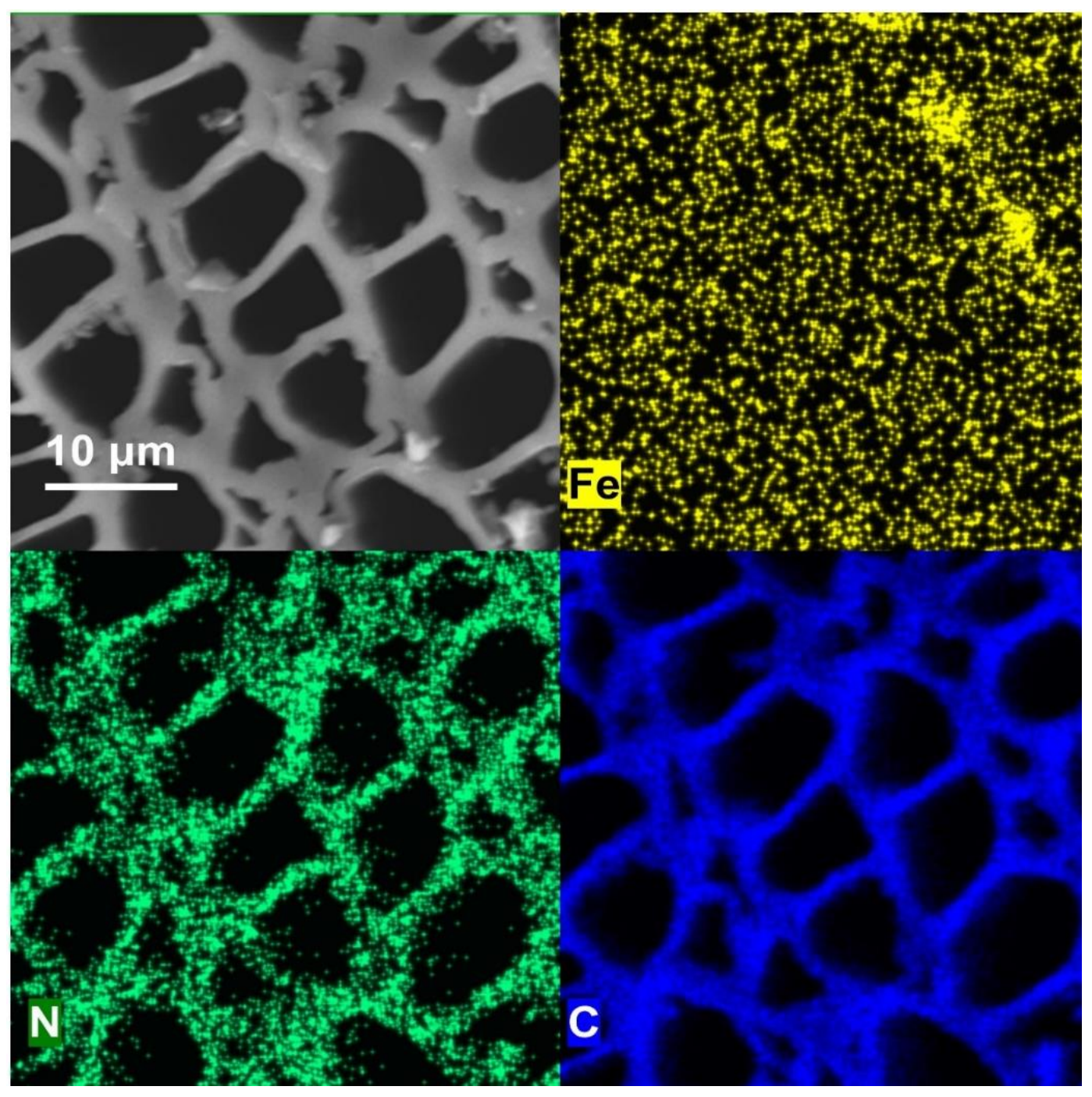

Figure S10. SEM-EDS mapping of SAC-FeN-WPC. 


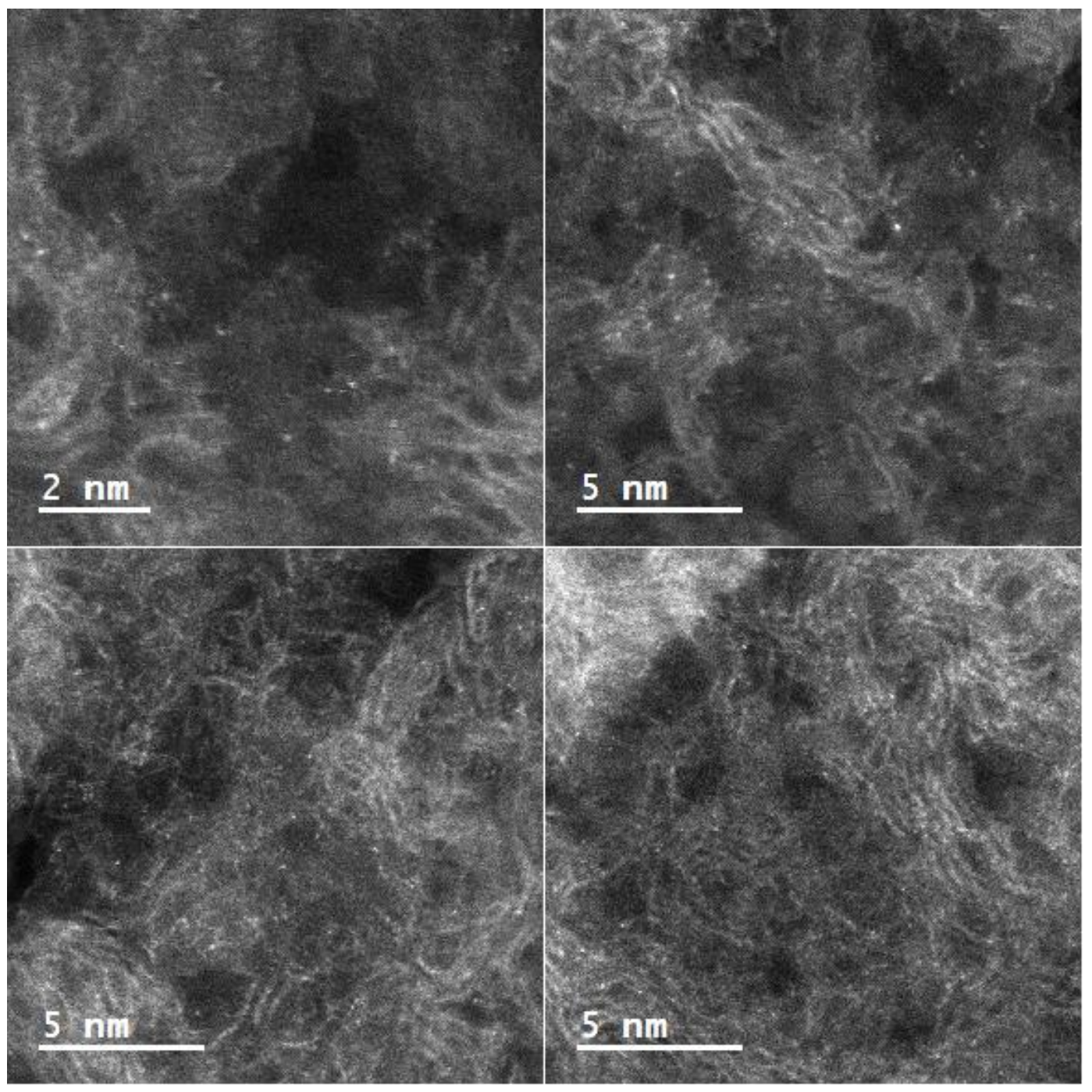

Figure S11. Aberration-corrected HAADF-STEM images of the SAC-FeN-WPC. 


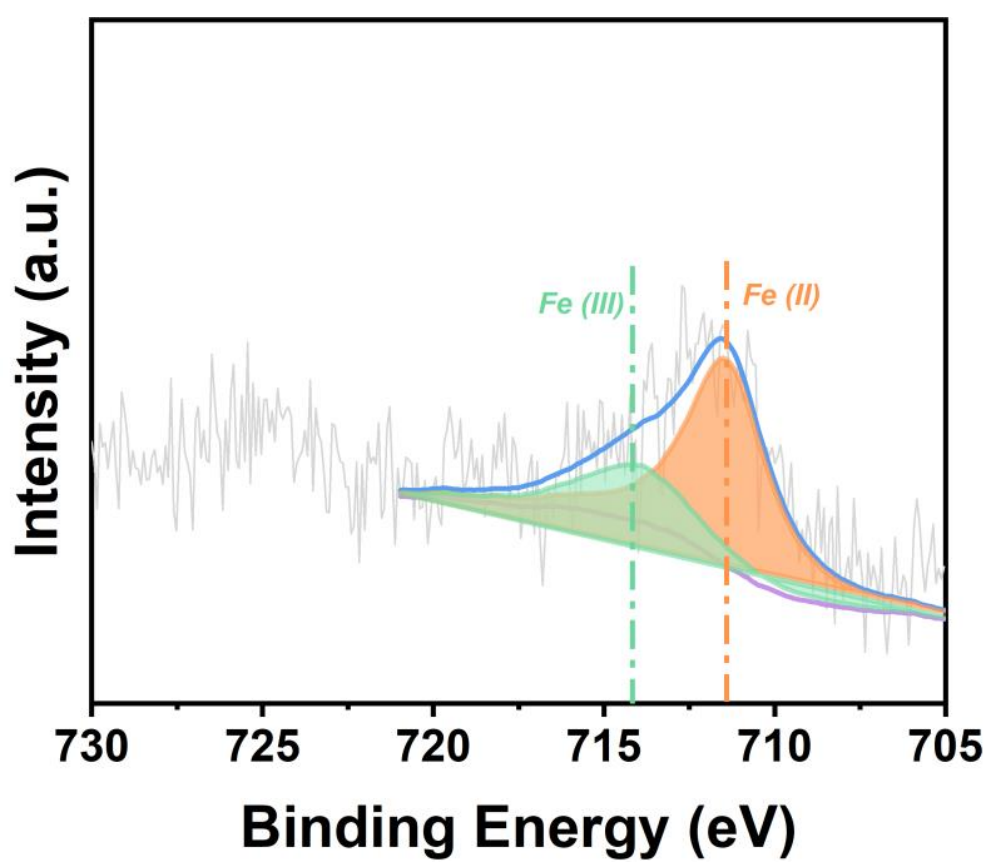

Figure S12. High-resolution XPS spectrum of Fe 2p for SAC-FeN-WPC. 


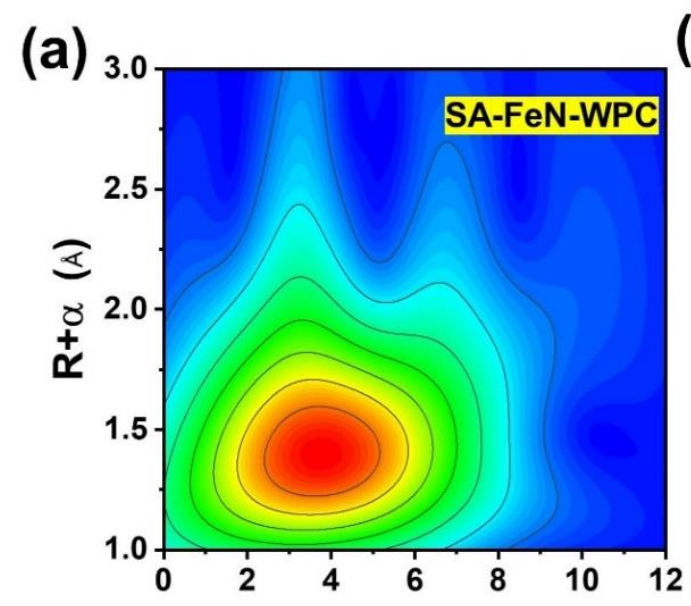

(b)
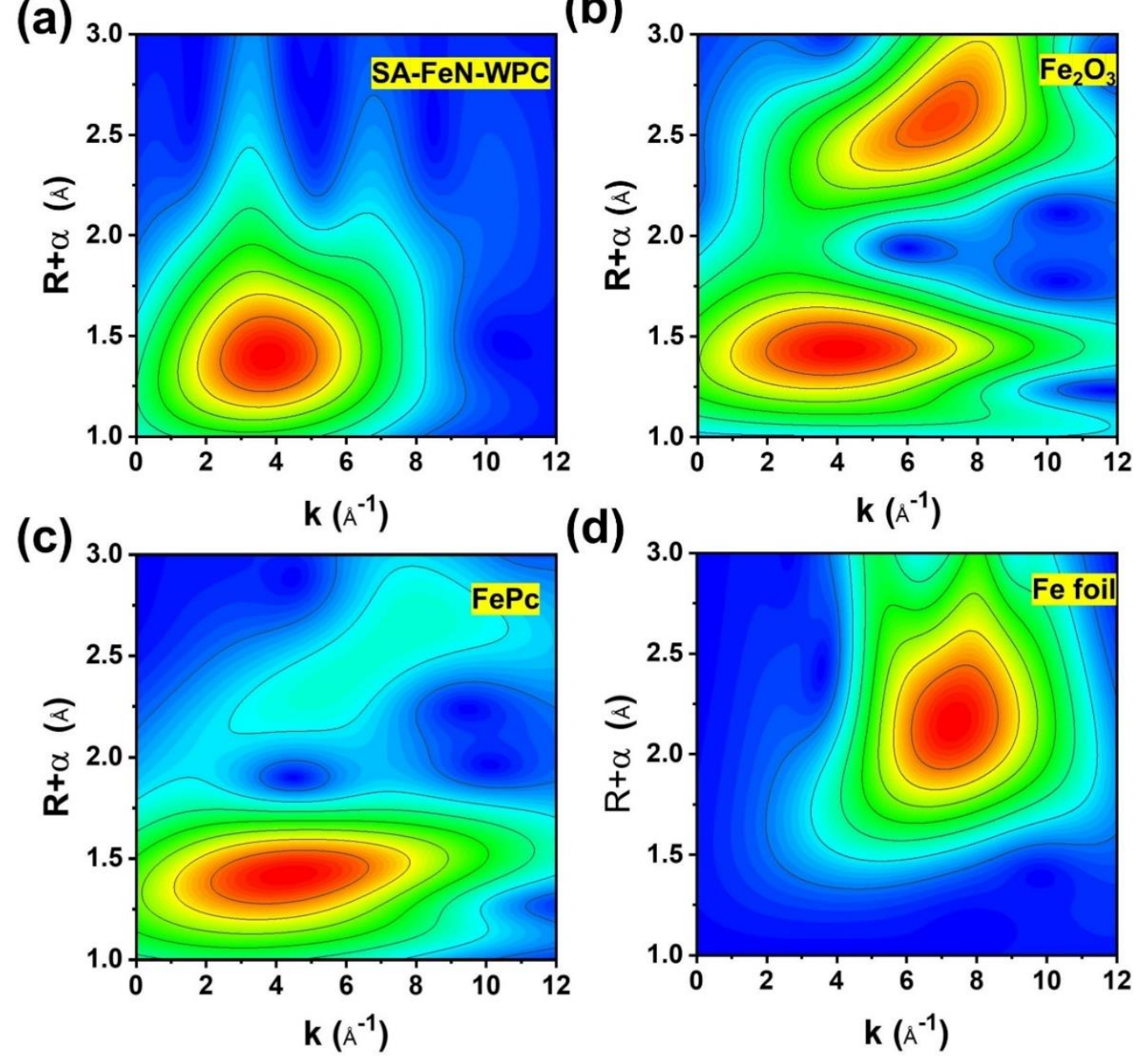

(d)

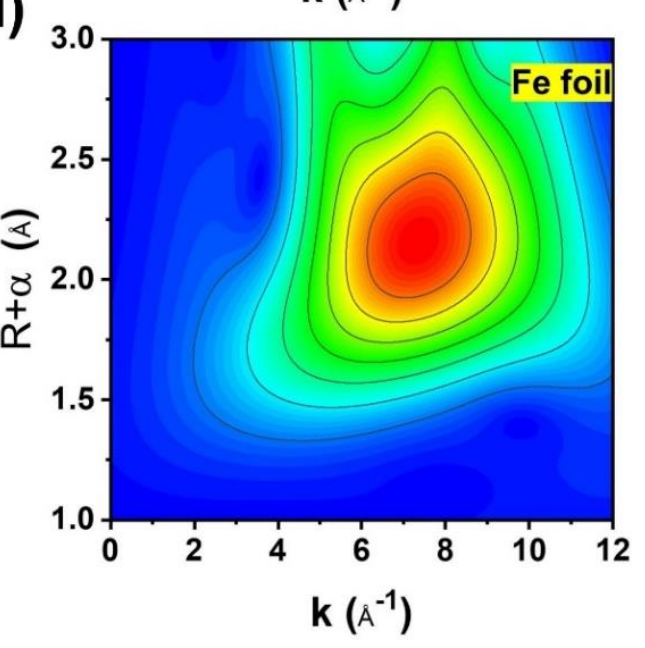

Figure S13. The Wavelet transform (WT) of the $k^{3}$-weighted Fe K-edge EXAFS for (a) SA-FeN-WPC, (b) $\mathrm{Fe}_{2} \mathrm{O}_{3}$, (c) iron phthalocyanine (FePc), and (d) Fe foil. 

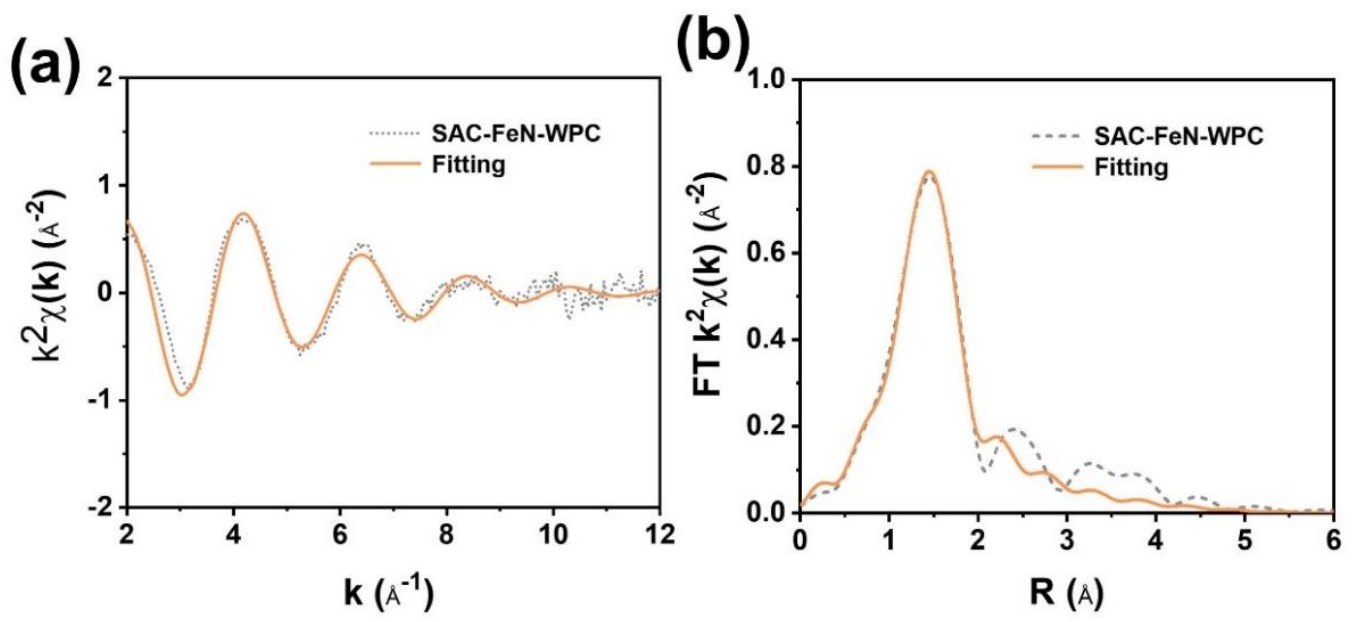

Figure S14. Fourier transform (FT) of the Fe K-edge EXAFS spectrum in (a) $k$ and (b) $R$ space and the corresponding fitting curve for SAC-FeN-WPC. 

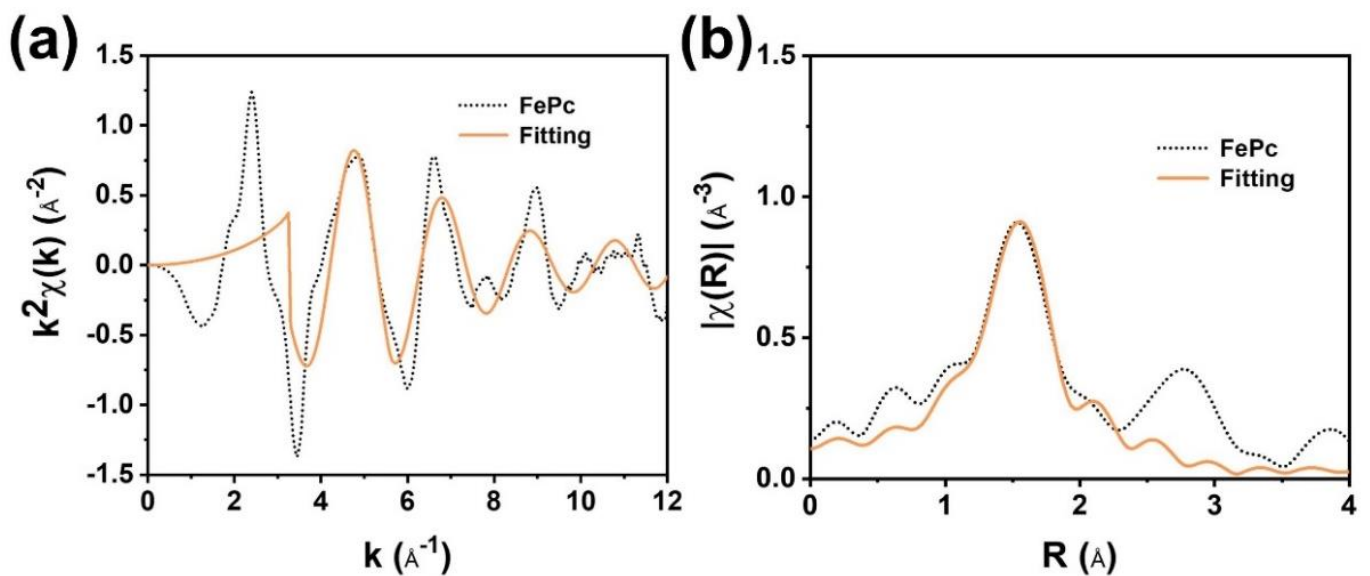

Figure S15. Fourier transform (FT) of the Fe K-edge EXAFS spectrum in (a) $k$ and (b) $R$ space and the corresponding fitting curve for iron phthalocyanine (FePc). 

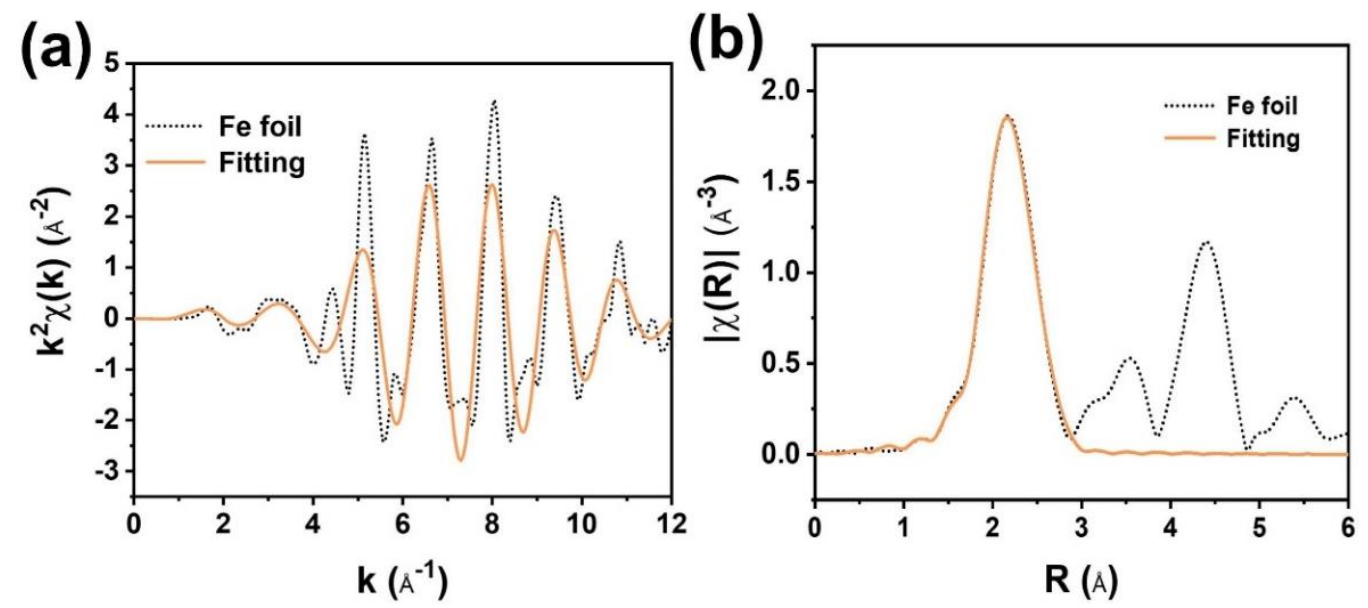

Figure S16. Fourier transform (FT) of the Fe K-edge EXAFS spectrum in (a) $k$ and (b) $R$ space and the corresponding fitting curve for $\mathrm{Fe}$ foil. 

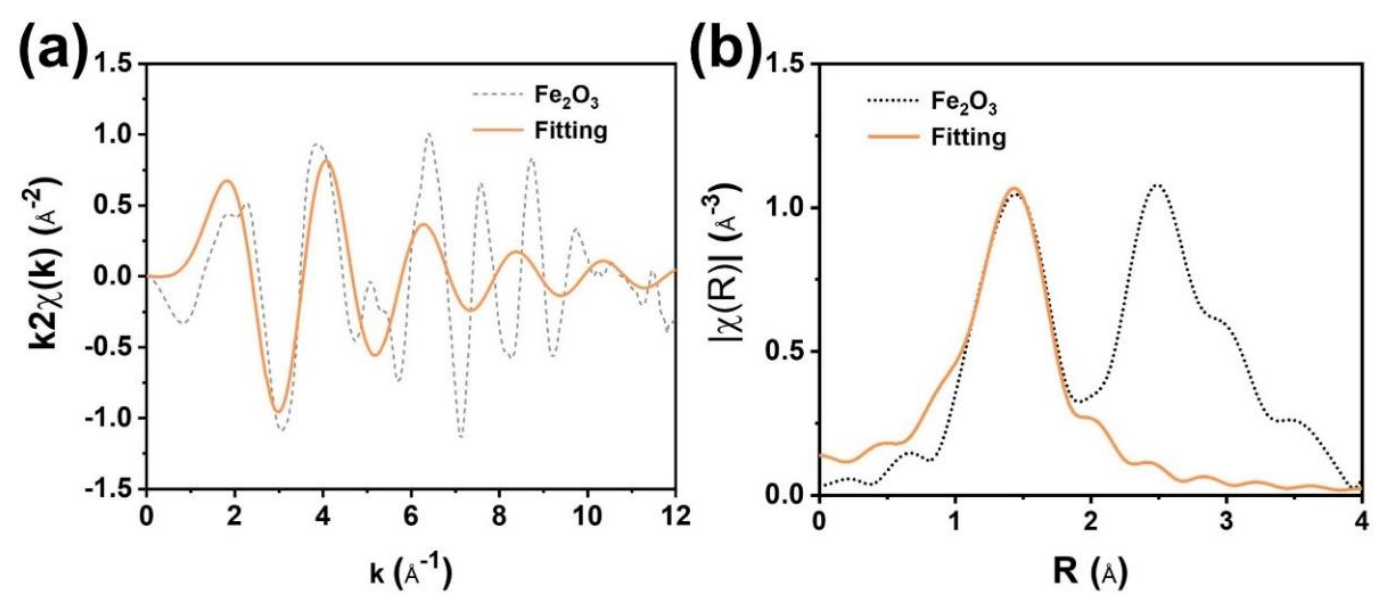

Figure S17. Fourier transform (FT) of the Fe K-edge EXAFS spectrum in (a) $k$ and (b) $R$ space and the corresponding fitting curve for $\mathrm{Fe}_{2} \mathrm{O}_{3}$. 
(a)

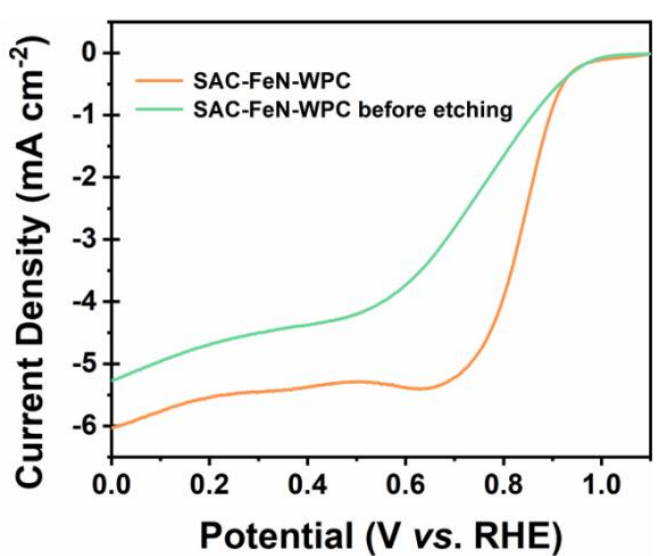

(b)

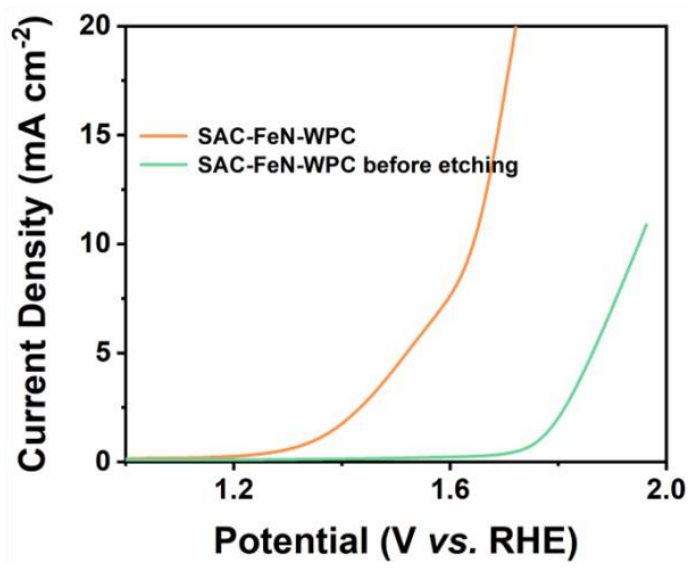

Figure S18. LSV (a) ORR and (b) OER curves for SAC-FeN-WPC before etching and SAC-FeN-WPC in $\mathrm{O}_{2}$-saturated $0.1 \mathrm{M} \mathrm{KOH}$ solution at the rotating rate of 1600 rpm. SAC-FeN-WPC exhibits a greatly enhanced ORR/OER reactivity after acid etching, suggesting that some inactive components have been removed after etching process. 
(a)

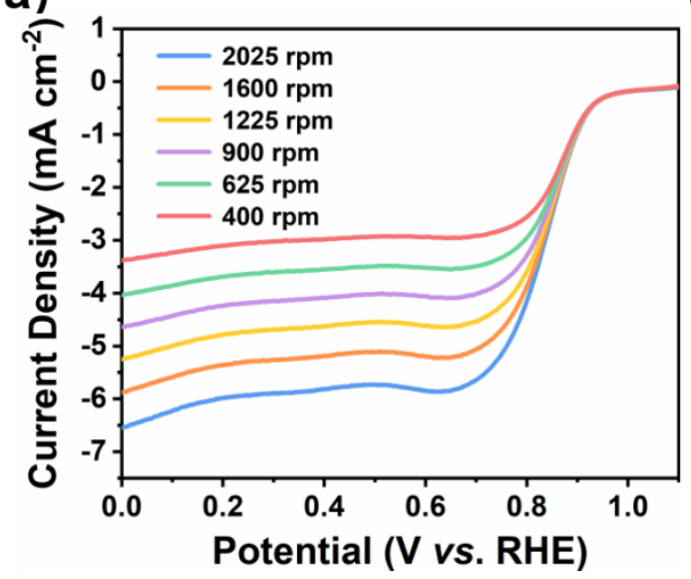

(b)

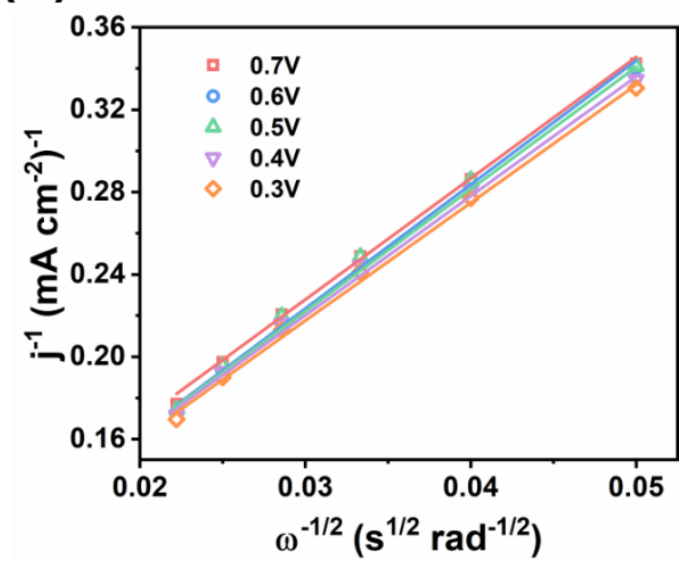

Figure S19. (a) LSV curves at different rotating rates for SAC-FeN-WPC. (b) K-L plots at different potentials of SAC-FeN-WPC. 
(a)

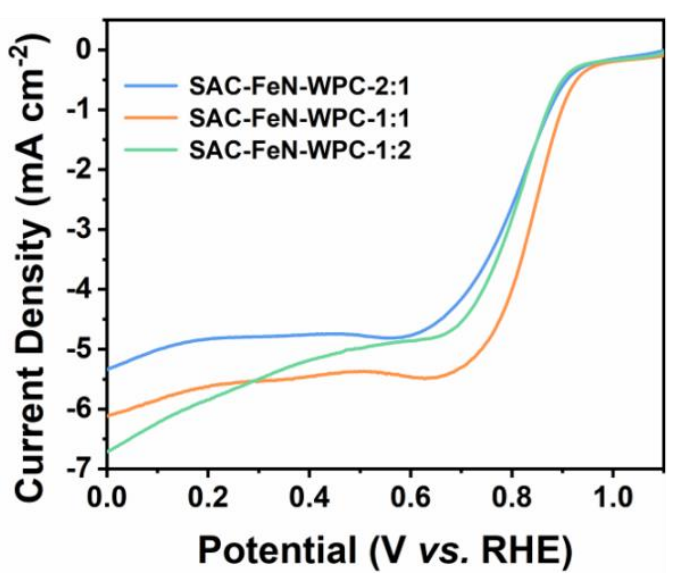

(b)

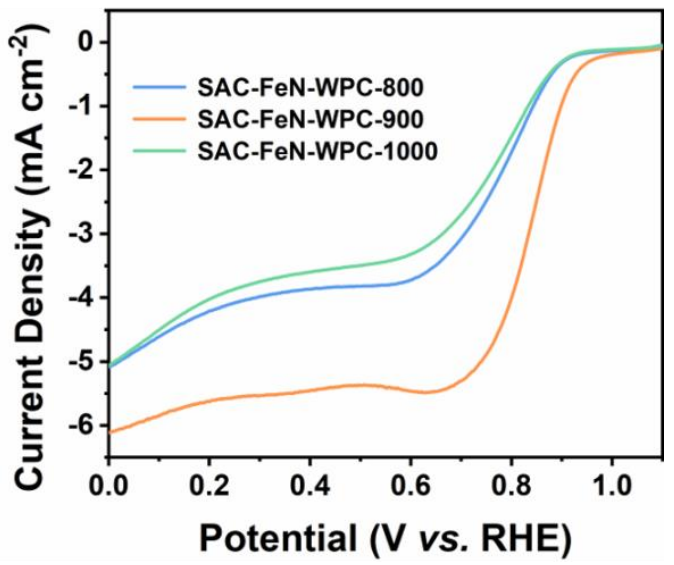

Figure S20. LSV ORR curves at the rotating rate of $1600 \mathrm{rpm}$ for (a)

SAC-FeN-WPC-2:1, SA-FeN-WPC-1:1 and SA-FeN-WPC-1:2, and (b)

SA-FeN-WPC-800, SA-FeN-WPC-900 and SA-FeN-WPC-1000. 
(a)

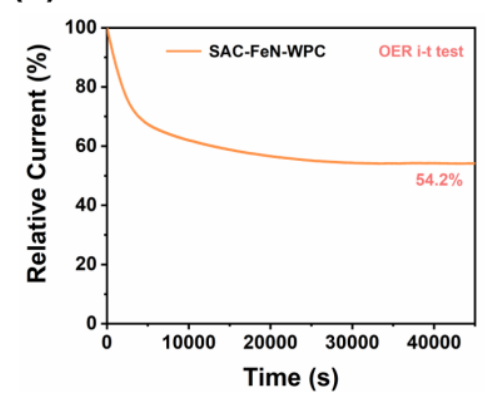

(b)

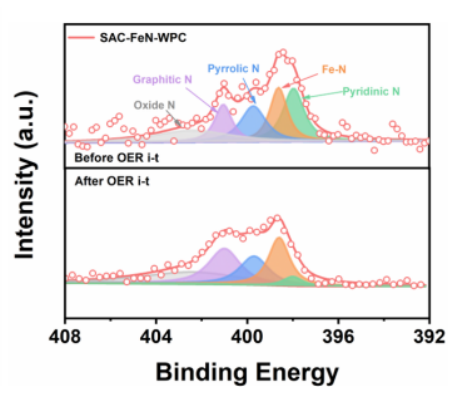

(c)

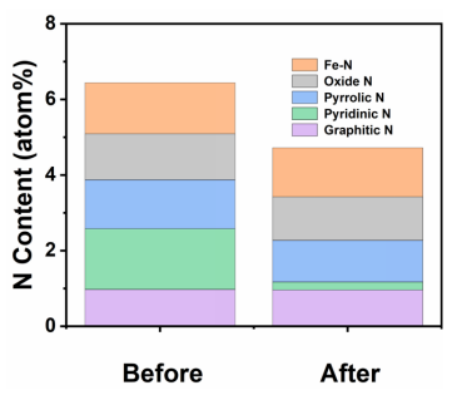

Figure S21. (a) Chronoamperometric curves for the OER of SAC-FeN-WPC in an $\mathrm{O}_{2}$-saturated 0.1 M KOH aqueous solution at $1600 \mathrm{rpm}$. (b) $\mathrm{N}$ 1s high-resolution XPS spectra of SAC-FeN-WPC before and after OER i-t test. (c) Contents of different N species in SAC-FeN-WPC before and after OER i-t test. 
(a)

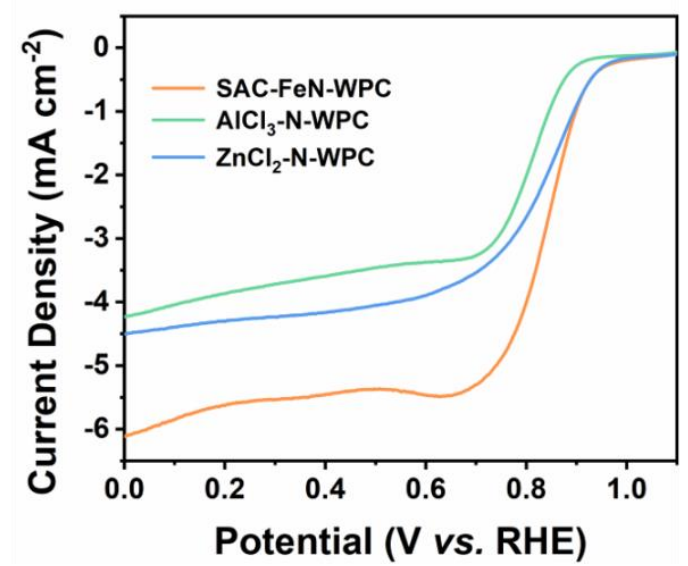

(b)

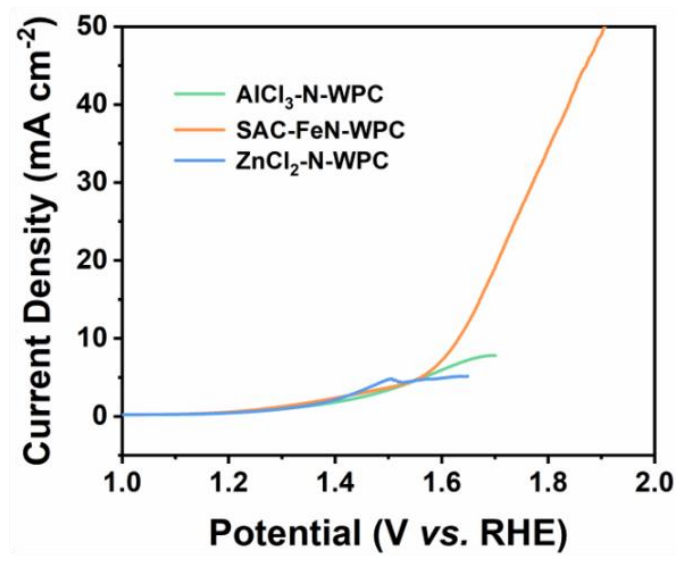

Figure S22. (a) LSV ORR curves at the rotating rate of $1600 \mathrm{rpm}$ for SAC-FeN-WPC, $\mathrm{AlCl}_{3}-\mathrm{N}-\mathrm{WPC}$, and $\mathrm{ZnCl}_{2}-\mathrm{N}-\mathrm{WPC}$. (b) LSV OER curves at the rotating rate of 1600 rpm for SA-FeN-WPC, $\mathrm{AlCl}_{3}-\mathrm{N}-\mathrm{WPC}$, and $\mathrm{ZnCl}_{2}-\mathrm{N}-\mathrm{WPC}$. 


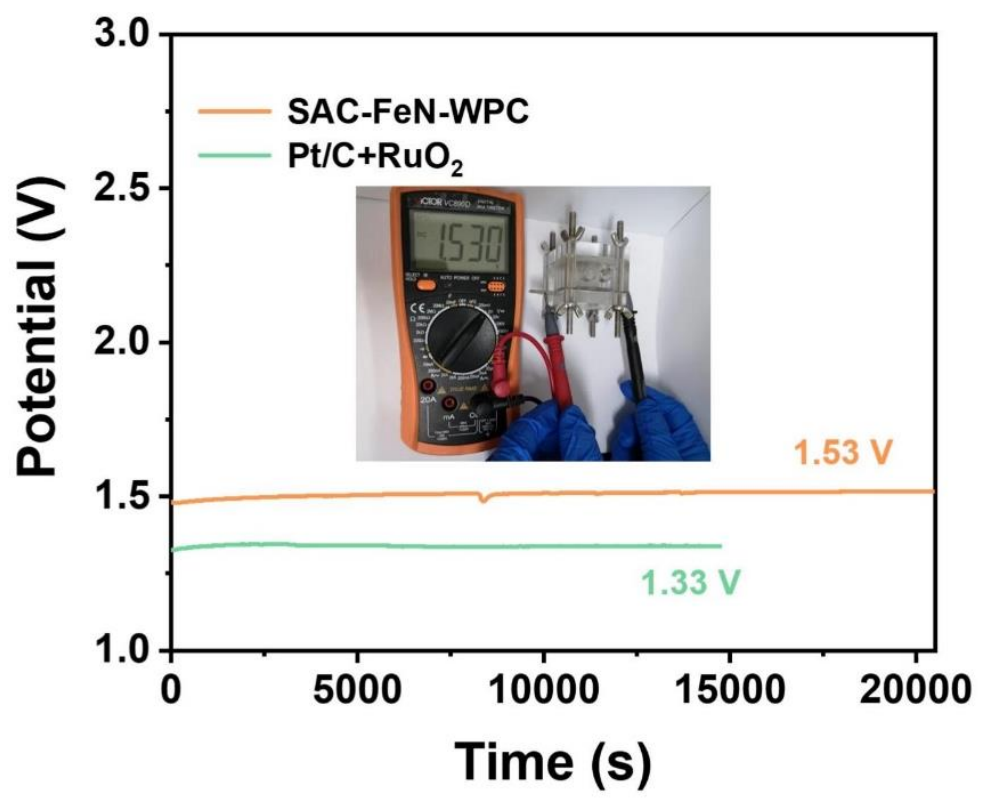

Figure S23. Open circuit plots of SAC-FeN-WPC and Pt/C+RuO 2 based ZABs. 


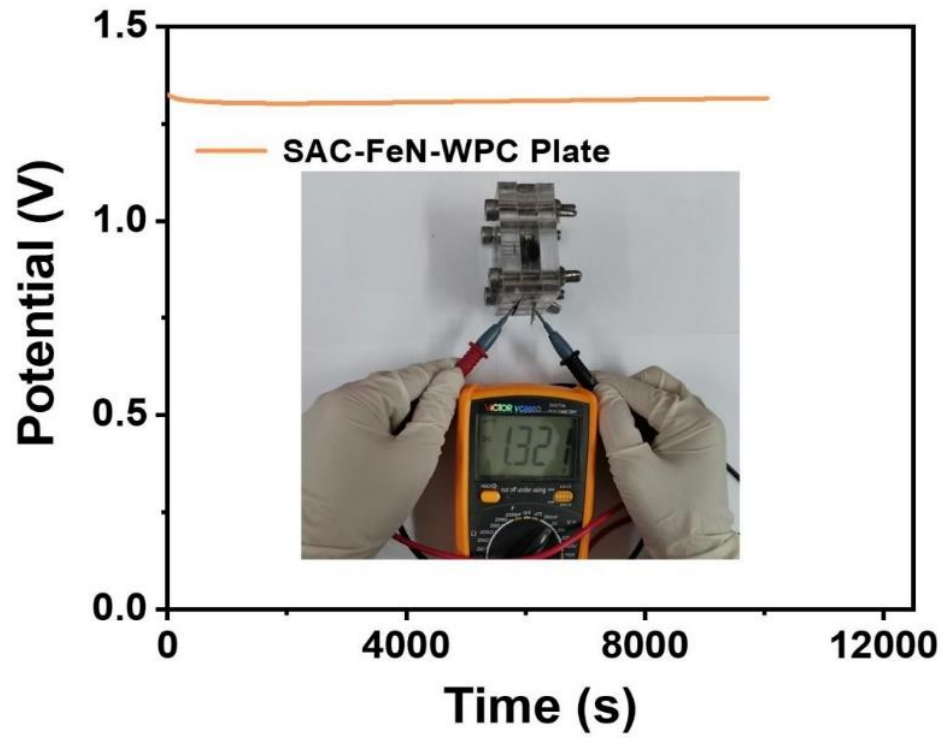

Figure S24. Open-circuit plot of SAC-FeN-WPC plate. 


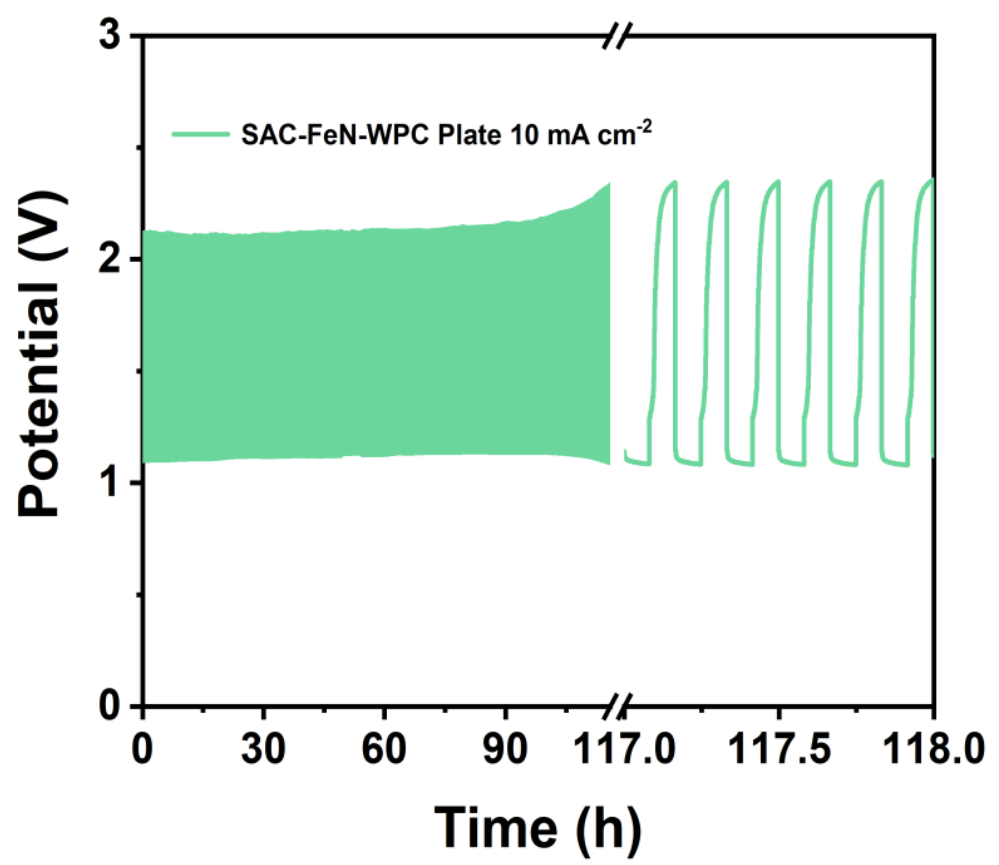

Figure S25. Galvanostatic discharge/charge cycling curves at $10 \mathrm{~mA} \mathrm{~cm}{ }^{-2}$. 
Table S1. BET surface area, pore volume and elemental contents of catalysts.

\begin{tabular}{|c|c|c|c|c|c|c|}
\hline \multirow[t]{2}{*}{ Samples } & \multirow{2}{*}{$\begin{array}{l}\text { BET surface } \\
\text { area } \\
\left(\mathrm{m}^{2} \mathrm{~g}_{-}^{1}\right)\end{array}$} & \multirow{2}{*}{$\begin{array}{c}\text { Pore } \\
\text { volume } \\
\left(\mathrm{cm}^{3} \mathrm{~g}^{1}\right)\end{array}$} & \multirow{2}{*}{$\begin{array}{l}\text { Micropore } \\
\text { volume } \\
\left(\mathrm{cm}^{3} \mathrm{~g}_{-}{ }^{1}\right)\end{array}$} & \multicolumn{3}{|c|}{$\begin{array}{c}\text { XPS analysis } \\
\text { (at } \%)\end{array}$} \\
\hline & & & & $\mathrm{C}$ & $\mathrm{N}$ & $\mathrm{O}$ \\
\hline WPC & 493.84 & 0.24 & 0.19 & I & I & I \\
\hline N-WPC & 781.78 & 0.47 & 0.32 & 92.83 & 2.38 & 4.79 \\
\hline SAC-FeN-WPC & 1183.23 & 0.86 & 0.33 & 85.90 & 6.44 & 7.31 \\
\hline $\mathrm{AlCl}_{3}-\mathrm{N}-\mathrm{WPC}$ & 862.14 & 0.54 & 0.19 & 88.27 & 4.02 & 7.09 \\
\hline $\mathrm{ZnCl}_{2}-\mathrm{N}-\mathrm{WPC}$ & 1642.38 & 0.85 & 0.46 & 90.24 & 3.58 & 4.96 \\
\hline
\end{tabular}


Table S2. Room temperature ${ }^{57} \mathrm{Fe}$ Mössbauer parameters for SAC- ${ }^{57} \mathrm{FeN}-\mathrm{WPC}$

\begin{tabular}{ccccccc}
\hline Catalyst & Peak & Assignment & $\begin{array}{c}\text { IS } / \mathrm{mm} \\
\mathrm{s}^{-1}\end{array}$ & $\begin{array}{c}\mathrm{QS} / \mathrm{mm} \\
\mathrm{s}^{-1}\end{array}$ & $\begin{array}{c}\Gamma / \mathrm{mm} \\
\mathrm{s}^{-1}\end{array}$ & Area/\% \\
\hline & $\mathrm{D} 1$ & $\begin{array}{c}\mathrm{Fe}(\mathrm{II})-\mathrm{N}_{4} \text { low spin } \\
\mathrm{Fe}^{2+} / \mathrm{Fe}^{3+} \text { middle } \\
\text { spin }\end{array}$ & 0.38 & 0.91 & 0.59 & 47.55 \\
& $\mathrm{D} 2$ & 0.41 & 2.11 & 0.60 & 45.27 \\
& $\mathrm{D} 4$ & $\mathrm{Fe}^{2+}$ high spin & 1.13 & 2.93 & 0.60 & 7.18 \\
\hline
\end{tabular}

IS is relative to $\alpha$-iron foil. $2 \Gamma$ is line width. 
Table S3. Summary of the catalytic activities of the reported composite electrocatalysts in $0.1 \mathrm{M} \mathrm{KOH}$.

\begin{tabular}{|c|c|c|c|c|}
\hline Catalysts & $\begin{array}{c}E_{1 / 2} \\
(\mathrm{~V} \text { vs. } \\
\text { RHE) }\end{array}$ & $\begin{array}{c}E_{j 10} \\
\text { (V vs. } \\
\text { RHE) }\end{array}$ & $\begin{array}{l}\Delta E \\
(\mathrm{~V})\end{array}$ & Reference \\
\hline SAC-FeN-WPC & 0.85 & 1.64 & 0.79 & This Work \\
\hline $\mathrm{Pt} / \mathrm{C}$ & 0.85 & N/A & N/A & This Work \\
\hline $\mathrm{RuO}_{2}$ & N/A & 1.57 & N/A & This Work \\
\hline $\mathrm{Fe} / \mathrm{N}-\mathrm{G}-\mathrm{SAC}$ & 0.87 & 1.58 & 0.71 & 54 \\
\hline $\mathrm{Fe}-\mathrm{N}_{x}-\mathrm{C}$ & 0.91 & 1.85 & 0.94 & 55 \\
\hline Fe-NSDC & 0.84 & 1.62 & 0.78 & 56 \\
\hline $\mathrm{M}-\mathrm{Fe}-\mathrm{NCNS}$ & 0.88 & 1.64 & 0.76 & 57 \\
\hline $\mathrm{Fe}-\mathrm{N}-\mathrm{C} / \mathrm{N}-\mathrm{OMC}$ & 0.93 & 1.76 & 0.83 & 58 \\
\hline Fe-TCNQ-Cl & 0.96 & 1.78 & 0.82 & 59 \\
\hline Fe-N-C-700 & 0.83 & N/A & N/A & 60 \\
\hline $\mathrm{Fe}-\mathrm{NCCs}$ & 0.82 & N/A & N/A & 61 \\
\hline N-Mo-holey & 0.85 & 1.65 & 0.80 & 62 \\
\hline Co-POC & 0.83 & 1.70 & 0.87 & 63 \\
\hline $\mathrm{CoN}_{4} / \mathrm{NG}$ & 0.87 & 1.61 & 0.74 & 64 \\
\hline NGM-Co & 0.79 & 1.74 & 0.95 & 65 \\
\hline $\mathrm{Co}_{3} \mathrm{O}_{4} / \mathrm{N}-\mathrm{rGO}$ & 0.79 & 1.72 & 0.93 & 66 \\
\hline $\begin{array}{c}\text { NC@Co-NGC } \\
\text { DSNCs }\end{array}$ & 0.82 & 1.64 & 0.82 & 67 \\
\hline $\mathrm{Fe}_{3} \mathrm{C} / \mathrm{Fe}_{2} \mathrm{O}_{3} @ \mathrm{NGNs}$ & 0.86 & 1.69 & 0.83 & 68 \\
\hline $\mathrm{N}_{2}-\mathrm{GNR}$ & 0.74 & 1.62 & 0.88 & 69 \\
\hline
\end{tabular}

